\title{
Survey of Health Knowledge Between Medical and Non-medical College Students in Fengtai Distract of Beijing
}

\author{
Ren Xukai, Li Yingying \\ Health Education Institute of Fengtai Center for Disease Control and Prevention, Beijing, China \\ Email address: \\ ren77beer@126.com (Ren Xukai) \\ To cite this article: \\ Ren Xukai, Li Yingying. Survey of Health Knowledge between Medical and Non-medical College Students in Fengtai Distract of Beijing. \\ American Journal of Health Research. Vol. 6, No. 4, 2018, pp. 93-97. doi: 10.11648/j.ajhr.20180604.16
}

Received: August 6, 2018; Accepted: September 14, 2018; Published: October 27, 2018

\begin{abstract}
Objective To know the attitudes, content, achieving approach of health knowledge among medical and non-medical college students, analyze their difference, provide the evidence for health education in college students. Methods Cluster random sampling method was used to recruit 660 college students from medical and non-medical colleges in Fengtai Distract of Beijing. The subjects were investigated by self-designed questionnaire, and there were 603 valid questionnaires. Results $72.6 \%$ of students believed that it was necessary to have health knowledge. College students were most interested in health lifestyle, accounting for $60.2 \%$, followed by reasonable dietary and nutrition (47.6\%), emergency aid and communal (43.9\%), mental health (37.4\%). The primary approach that college students obtained health knowledge was mobile phones and network, accounting for $67.2 \%$, followed by paper media $(63.0 \%)$, television and video $(55.4 \%)$. There were significant difference in healthy lifestyle, reasonable diet and nutrition, mental health, infectious disease prevention, chronic disease prevention, public places reliability analysis between medical and non-medical students $(\mathrm{P}>0.05)$ The difference in attitude towards knowledge and achieving approach were not statistically significant $(\mathrm{P}>0.05)$. Conclusions College students' have the positive attitude towards health knowledge. Medical and non-medical students focus on different health content. New media technology should be strengthened to cultivate college students' health knowledge in college students.
\end{abstract}

Keywords: College Student, Health Knowledge, Survey, Medical

\section{Introduction}

Today, there are many surveys and researches on the KAP of health status, oral knowledge and infectious disease between medical and non-medical college students [1-4], while little is done on the comparison analysis of their health knowledge. In order to learn about the demands for health knowledge between medical students and non-medical college students in Fengtai District, Beijing, the author did a survey and research on medical and non-medical college students in Fengtai District, with the aim to provide references for developing well-directed health education, so that the health conscience and professional level of the college students can be improved.

\section{Objective and Method}

\subsection{Objective}

From March to May, 2015, we randomly selected medical and non-medical students from 2 colleges in Fengtai District, Beijing and sent out 660 questionnaires. 603 effective questionnaires were returned, and the rate was $91.4 \%$.

\subsection{Method}

The questionnaire was designed by the investigator himself on the basis of professional consulting and referring to relative references; the method of cluster random sampling is adopted, and altogether 660 students in these two colleges received questionnaire investigation made by trained investigators. The questionnaire includes the demands for health knowledge, the approach of acquiring health knowledge, and the attitude of acquiring health knowledge etc. The method of anonymous self-filling was adopted. After they have been answered, the questionnaires are collected on the spot.

\subsection{Statistic Analysis}

After establishing and verifying the database, the software 
SPSS17.0 is adopted to analyze the data; the statistical method is checked by $\chi^{2}$, if $\mathrm{P}<0.05$, it means that the difference has statistical significance.

\section{Results}

\subsection{General Condition}

Students being surveyed have an average age of 19.8, with the youngest 17 and the oldest 28. There are altogether 317 non-medical college students, (among them 140 are boys (44.2\%) and 177 are girls (58.8\%)) 140 males (44.2\%) and 177 females $(58.8 \%)$. And there are 286 medical college students, (among them 111 are boys $(38.8 \%)$ and 175 are girls (61.2\%)) 111 males (38.8\%) and 175 females (61.2\%). (There is no statistical significance on the sex structure between medical and non-medical college students) The gender difference between medical students and non-medical students was not statistically significant $\left(\chi^{2}=1.773, \mathrm{P}>0.05\right)$.

\subsection{The Attitude Towards Health Knowledge and Propaganda Material}

$72.6 \%$ college students think it necessary to acquiring health knowledge (think that acquiring health knowledge is necessary), $24.8 \%$ college students think it common (think that it is just so so), and only $2.2 \%$ college students think it irrelevant (think that it doesn't matter at all). The difference of the attitude towards propaganda materials on health education has statistical significance between medical and non-medical college students $(\mathrm{P}=0.034)$ (has statistical significance, which $\mathrm{P}=0.034$ ), while the difference on the attitude towards health knowledge as well as its significance doesn't have statistical significance, with all $\mathrm{P}>0.05$ (which $\mathrm{P}>0.05$ ). See Table 1 .

Table 1. Survey on College Students' Attitude towards Acquiring Health Knowledge [Number of People, (\%)].

\begin{tabular}{|c|c|c|c|c|}
\hline Contents of Survey & $\begin{array}{l}\text { MMedical College } \\
\text { Students }(\mathbf{n}=\mathbf{2 8 6}) \\
\end{array}$ & $\begin{array}{l}\text { NNon-medical College } \\
\text { Students }(n=317)\end{array}$ & $\chi \chi^{2}$ Value & P P Value \\
\hline \multicolumn{5}{|c|}{ The Attitude towards Acquiring Health Knowledge } \\
\hline Necessary & $208(72.7)$ & $230(72.6)$ & 1.544 & 0.462 \\
\hline Just So So & $74(25.9)$ & $78(24.6)$ & & \\
\hline Doesn't Matter & $4(1.4)$ & $9(2.8)$ & & \\
\hline \multicolumn{5}{|c|}{ The Attitude towards Propaganda Materials on Health Education } \\
\hline Welcome & $197(68.9)$ & $212(66.9)$ & 6.739 & 0.034 \\
\hline Doesn't Matter & $82(28.7)$ & $83(26.2)$ & & \\
\hline \multicolumn{5}{|c|}{$\begin{array}{l}\text { The Attitude towards the Importance of the Propaganda Materials on } \\
\text { Health Education }\end{array}$} \\
\hline Necessary & $125(43.7)$ & $159(50.2)$ & 2.824 & 0.244 \\
\hline Just So So & $141(49.3)$ & $135(42.6)$ & & \\
\hline Not very Important & $20(7.0)$ & $23(7.3)$ & & \\
\hline
\end{tabular}

\subsection{Contents of Health Knowledge}

Among the multiple choice of the contents of health knowledge, 363 students $(60.2 \%)$ choose healthy lifestyle as their most interested contents of health knowledge, 287 students $(47.6 \%)$ choose reasonable diet and nutrition, while the others choose self-rescue and mutual rescue of emergency disease, health knowledge on psychology and knowledge on safely use medicine etc.

The differences between medical and non-medical college students on healthy lifestyle, reasonable diet and nutrition, mental health, prevention of infectious disease and the prevention of chronic disease have statistical significance, with all $\mathrm{P}>0.05$. (which $\mathrm{P}<0.05$.) See Table 2 .

Table 2. The Comparison of the Survey to College Students towards the Contents on Health Knowledge [Number of People (\%)].

\begin{tabular}{|c|c|c|c|c|}
\hline Contents of Health Knowledge & Medical College Student $(n=286)$ & Non-medical College Student(n=317) & $\chi^{2}$ Value & P Value \\
\hline Healthy Lifestyle & $195(68.2)$ & $168(53.0)$ & 14.469 & 0.000 \\
\hline Reasonable Diet and Nutrition & $151(52.8)$ & $136(42.9)$ & 5.902 & 0.015 \\
\hline Self-rescue and Mutual rescue of emergency disease & $122(42.7)$ & $143(45.1)$ & 0.367 & 0.544 \\
\hline Psychological Health & $118(41.3)$ & $106(33.4)$ & 3.938 & 0.047 \\
\hline Knowledge on Safely Use Medicine & $73(25.5)$ & $70(22.1)$ & 0.985 & 0.321 \\
\hline Prevention of Infectious Disease & $48(16.8)$ & $84(26.5)$ & 8.299 & 0.004 \\
\hline Prevention of Chronic Disease & $27(9.4)$ & $61(19.2)$ & 11.591 & 0.001 \\
\hline Sexy and Reproductive Health & $40(14.0)$ & $37(11.7)$ & 0.723 & 0.395 \\
\hline
\end{tabular}

\subsection{Approaches of Acquiring the Health Knowledge}

Among the multiple choice of the approaches of acquiring the health knowledge, 405 students $(67.2 \%)$ choose "Through Mobile Phone and Computer”, 380 students (63.0\%)choose "Through Paper Media such as Books, Newspaper, Magazines etc", while others choose "TV, Broadcast", "School Courses on Health Education", "Learn from other People", "Propaganda Material" and "Poster and Publicity Column" etc.

There is no statistically significant difference in access to health knowledge between medical college students and non-medical college students, with all $\mathrm{P}>0.05$. See Table. 
Table 3. College Students' Approaches of Acquiring the Health Knowledge [Number of People (\%)].

\begin{tabular}{|c|c|c|c|c|}
\hline $\begin{array}{l}\text { The Approaches of Acquiring Health } \\
\text { Knowledge }\end{array}$ & $\begin{array}{l}\text { Medical College Student } \\
(\mathrm{n}=\mathbf{2 8 6})\end{array}$ & $\begin{array}{l}\text { Non-medical College Students } \\
(\mathrm{n}=317)\end{array}$ & $\chi^{2}$ Value & P Value \\
\hline School Course on Health Education & $84(29.4)$ & $88(27.8)$ & 0.191 & 0.662 \\
\hline Book, Newspapers, Magazines & $183(64.0)$ & 197(62.1) & 0.219 & 0.640 \\
\hline TV, Broadcast & $164(57.3)$ & $170(53.6)$ & 0.840 & 0.359 \\
\hline Learn from Others & $58(20.3)$ & $54(17.0)$ & 1.047 & 0.306 \\
\hline Poster and Publicity Column & $13(4.5)$ & $10(3.2)$ & 0.793 & 0.373 \\
\hline Propaganda Material & $20(7.0)$ & $22(6.9)$ & 0.001 & 0.980 \\
\hline Mobile Phone, Computer & $198(69.2)$ & $207(65.3)$ & 1.054 & 0.305 \\
\hline Others & $1(0.3)$ & $5(1.6)$ & 2.300 & 0.129 \\
\hline
\end{tabular}

\subsection{The Credibility of the Source of Health Knowledge}

Among the multiple choice of the credibility of the source of health knowledge, 442 college students choose medical agencies, secondly are schools (290 students) and government offices (225 students), while the lowest credibility are public places. Except the option of government offices, the difference in credibility between medical and non-medical college students is statistically significant $(\mathrm{P}<0.05)$. (on the credibility has statistical significance). See Table 4.

Table 4. Recognition of Credibility of the Sources of Health Knowledge Among College Students [Number of People (\%)].

\begin{tabular}{|c|c|c|c|c|}
\hline $\begin{array}{l}\text { Sources of Acquiring Health } \\
\text { Knowledge }\end{array}$ & $\begin{array}{l}\text { Medical College Students } \\
(\mathrm{n}=\mathbf{2 8 6})\end{array}$ & $\begin{array}{l}\text { Non-medical College Students } \\
(n=317)\end{array}$ & $\chi^{2}$ Value & P Value \\
\hline School & $153(53.5)$ & $137(43.2)$ & 6.363 & 0.012 \\
\hline Public Places & $27(9.4)$ & $63(19.9)$ & 12.889 & 0.0003 \\
\hline Medical Agencies & $223(78.0)$ & $219(69.1)$ & 6.067 & 0.014 \\
\hline Government Offices & $102(35.7)$ & $123(38.8)$ & 0.633 & 0.426 \\
\hline
\end{tabular}

\section{Discussion}

This survey is an anonymous questionnaire survey, which is a comparative study conducted among different types of college students according to match with the age and gender. The questionnaire is good-designed, well-organized and effective.

(In the analysis of the credibility of the sources of health knowledge,) In the credibility analysis of health knowledge sources, medical agencies have the highest credibility. It is possibly that medical agencies, thanks to its characteristics and professional advantages, fully understand and grasp health knowledge. There are differences between medical college students and non-medical college students in the credibility, which may be caused by the professional background of medical college students, as a result, the credibility of resources from medical agencies and schools is high, while the credibility of the health knowledge from public places is rather low.

According to the survey, the contents of health knowledge that college students most interested in are in sequence "healthy lifestyle", "reasonable diet and nutrition knowledge", "self-rescue and mutual rescue of emergency diseases" and "knowledge of psychological health" etc. This is the same as Gao Huan [5]'s survey, in which the health knowledge college students most interested in are in sequence "the harm of smoking", "reasonable diet and nutrition knowledge", "healthy lifestyle", "self-rescue and mutual rescue of emergency diseases" and "psychological health". In addition, it is similar to the investigations made by Jia chengzhi [6], in which shows that the top three demands for health knowledge are respectively "healthy lifestyle", "self-rescue and mutual rescue of emergency diseases" and "psychological health". In this research, compared with non-medical college students, medical college students have a high proportion on the options of healthy lifestyle, reasonable diet and nutrition knowledge and psychological health, while have a low proportion on the options of prevention of infectious diseases and chronic diseases. The reason maybe that medical college students have already had large medical knowledge reserve from the learning of basic courses, so they are prone to learn more knowledge about healthy lifestyle, diet and nutrition etc.

The issue shows that college students mainly ways to acquire healthy knowledge are from mobile phones and computers, others from books, newspapers, magazines, TVs, broadcast and school courses on health education etc. The difference between medical and non-medical college students has no statistical significance. This is the same with the survey made by Li Haihong [7] etc on college students' approaches of acquiring health knowledge, in which the top 5 approaches are in sequence network, TV, books, learning from others and publicity of health. Also, it is the same with the surveys made by Zhao liang [8] and Yu hongmei [9], which shows that the college students' main sources of health knowledge are internet, books, magazines and newspapers etc. It may be that it's very convenient for college students to acquire health knowledge from new media such as network and mobile phone. In addition, college students are good at accepting new things, following the developing trends of the times, and good at using network to learn and understand health knowledge (learning and understanding health knowledge from network). 
However, the credibility of self-learning and acquiring health knowledge through network is open to question [10]' The reason is that there are so many healthy contents available via virtualized networks on mobile phones and computers that authenticity and accuracy cannot be guaranteed. (because through virtualized network in mobile phone and computer, students can acquire various contents of health, which authenticity and accuracy cannot be ensured.) It is the responsibility of the health teaching staff on how to instruct college students to receive health education from network [11]. It is also considerable on how to explore and extend health education through network, which has great challenge for health education workers who are in new era.

Some investigations [12] find that there are differences among college students of various grades on the oral health, this is the deficiency of this investigation. However, this investigation objectively compares differences between medical college students and non-medical college students on health knowledge, resources of acquiring the knowledge and their credibility, so as to provide certain scientific basis for further exploring how different types of college students can fully take advantages of new media such as internet etc., broaden health education modes [13]' guide college students to learn health college knowledge and skills, nudge them to cultivate a healthy lifestyle and improve quality of life, and ensure the sustainable development of the national health education.

\section{Conclusion}

The investigation shows that the college students' attitude towards health knowledge and the propaganda materials of health education is positive. More than 70 percent of the students considered it necessary to acquire health knowledge. Attitude is everything, and such results give positive impetus to the continued development of health education in college students. The majority number (68.9\%) of the college students believed that access to health education materials (tools) was also welcomed, and there was no statistically significant difference in attitudes between medical students and non-medical students in these two aspects. It shows that it is necessary and significant to develop health education for university students by government or formal institutions.

According to the survey, the contents of health knowledge that college students most interested in are in sequence "healthy lifestyle", "reasonable diet and nutrition knowledge", "self-rescue and mutual rescue of emergency diseases" and "knowledge of psychological health" etc.

College students mainly ways to acquire healthy knowledge are from mobile phones and computers, others from books, newspapers, magazines, TVs, broadcast and school courses on health education etc. In addition, this investigation finds that the proportion of acquiring health knowledge from posters and publicity column among college students is low, the reason needs further researching, but it is suggested that colleges should assist the school courses of health education through improving the building of publicity column and distributing propaganda materials to college students, so as to provide comprehensive and systematic health education to college students [14-15].

Thus, combined with the actual situation of China's health education system, The following three important inferences can be drawn from this paper: (1) government or non-government health education organizations (NGO) should always be on the dominant position of health education, therefore it should set up leadership organization which integration of students, health education works and university to carry out targeted health education work for the long-term, and dynamically. (2) Health knowledge should be disseminated in a way more suitable for college students, in which the role of multimedia is more important, and propaganda materials should be developed and produced from traditional paper media to multimedia. (3) College students healthy education on new environment should combine the characteristics of The Times and the demand of college students and will strengthen healthy education for smoking cessation, meal balance, healthy lifestyle, etc.

\section{References}

[1] Zhang min, Huang yue, Liu meijun et al. An analysis of health literacy status of medical students and non-medical students in Bengbu City [J]. Chinese Journal of School Health. 2015, 36(01):121-123.

[2] Li baikun, Zhan yucan, Li jing, et al. An analysis of lower grade students 'state of sub- health and correlative factors in a university of Chinese medicine[J] Chinese Journal of Disease Control \& Prevention, 2018, 22(01):66-69.

[3] Chen fa, He baochang, Liu mengyan. Investigation and analysis on oral hea-lth status and practice for college students in Fuzhou [J]. Chinese Journal of School Health. 2015, $36(01): 31-33$.

[4] Chen jundao, Wang xiaoguo, Rong qingxiu, et al. Survey on biosafety and knowledge, attitude and practice of infectious disease among students in Anhui province [J]. Chinese Journal of Health Education, 2015, 31(05):464-466+489.

[5] Jia chengzhi. Investigation and Analysis of College Students' Health Problems and Health Education Needs [J] Technology and management, 2016, 18(05):109-113.

[6] Li Haihong, Li Qian, Yang Tao. Research on Common Health Problems among College Students in Beijing and their Approaches of Acquiring the Health Knowledge [J]. Chinese Journal of School Health. 2014, 35(3):444-446.

[7] Zhao liang, Cheng xiangqian, Cao ru, et al. Present situation about the health literacy of junior college students in Nanjing Medical University [J] 2016, 16(03):200-204.

[8] Yu hongmei, Chengyan. Jiang shengwen. Research on College Students' Psychological Health Education under Modern Media [J]. News Front, 2015(01):184-185.

[9] Zhou weiwei, Luo chunhua, Fan cunxin, et al. A study on the status and influential factors of health literacy among undergraduate students in Guangzhou City [J]. Chinese Journal of Disease Control and Prevention 2014, 18(07):654-658 
[10] Wang beibei. Study on Psychological Health Education for University Students in Network Environment -take Northwest A\& F University as an example [J]. Northwest A\& F University, 2013.

[11] Zeng Yulan, Xia Lin. Survey on knowledge, behavior and attitude of oral health among medical students of different grades [J]. Occupation and Health. 2013, 29(17):2237-2239.

[12] Chen ping, Jia zhonghua, Zhang peng. A preliminary study on the mental health education mode of college students under the "Internet + " environment [J]. Journal of Chongqing Electric Power College, 2018, 23(01):10-12+15.

[13] Zhang zuxi, Liao youguo. The Development Status, Challenges and Countermeasures of Mental Health Education in Colleges and Universities [J] Journal of Changchun University of terchnology (Higher Education Study Edition) 2018, 23(01):10-12+15.

[14] Yang xu. Investigation and Intervention Studies of Medical College Student Health Knowledge and Health Behavior [D] Tianjin Medical University, 2013.

\section{Biography}

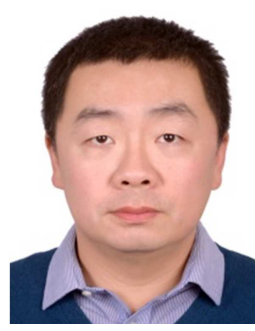

Ren Xukai, male. He was born in Beijing on November 21, 1976. As an associate chief physician in Fengtai district center for disease prevention and control of Beijing. Academic performance: He has been a health education professional for more than 10 years. He has won the project award from Ministry of Public Health of China once and scientific and technological progress award of fengtai district twice. He have published 14 academic papers as the first author and completed 4 research projects in health education fields. 